\title{
Proteção multinível da liberdade sexual: crime de violação no direito internacional e o caso Bemba Gombo
}

\author{
Multilevel Protection of Sexual Freedom: \\ Crime of Rape in International Law \\ and the Bemba Gombo Case
}

\section{Protection à plusieurs niveaux de la liberté sexuelle: crime de viol en droit international et affaire Bemba Gombo}

\section{Felipe Augusto Lopes Carvalho*}

SumÁrio: I. Introdução. II. Proteção multinível dos direitos e Tribunal Penal Internacional. III. Crimes sexuais no direito internacional penal: evolução histórica. IV. Avanços e retrocessos do caso Bemba Gombo. V. Conclusões. VI. Bibliografia.

* Universidade de Coimbra, Portugal; ORCID ID: https://orcid.org/0000-0002-5765-8 36X,felipe.alc1@gmail.com. 
Resumo: O presente trabalho objetiva analisar, à luz da proteção multinível dos direitos humanos, a evolução do tratamento conferido pelo direito internacional penal aos crimes de natureza sexual, em especial à violação, desde a sua gênese nos primeiros documentos do moderno direito de guerra, Convenções de Haia e Tribunais Militares pós-Segunda Guerra, passando pelas contribuições materiais e processuais dos tribunais penais ad hoc para antiga Iugoslávia e Ruanda, até chegar ao Estatuto de Roma do Tribunal Penal Internacional (TPI). Por fim, analisar-se-á o caso Jean Pierre Bemba Gombo, recentemente julgado pelo TPI, e as contribuições e retrocessos que podem ser observados nesse julgamento para o desenvolvimento da jurisprudência internacional sobre o tema.

Palavras-chave: crimes sexuais, direito internacional penal, Tribunal Penal Internacional, Bemba Gombo, justiça.

ABSTRACT: The purpose of this paper is to analyze, in light of the multilevel human rights protection, the evolution of the treatment given by international criminal law to sex crimes, in particular to rape, since its genesis in the first documents of the modern law of war, the Hague conventions and the post-Second War tribunals, following the material and procedural contributions by the ad hoc International Criminal Tribunals for the former Yugoslavia and Rwanda, until the Rome Statute of the International Criminal Court (ICC). Finally, the paper will examine the judgment of Jean Pierre Bemba Gombo, recently tried by the ICC, the contributions and setbacks of this case law to the development of international jurisprudence on the subject.

Key words: sexual crimes, international criminal law, International Criminal Court, Bemba Gombo, justice.

RÉSUMÉ: L'article vise à analyser, à la lumière de la protection à plusieurs niveaux des droits de l'homme, l'évolution du traitement réservé par le droit international pénal aux délits à caractère sexuel, notamment au viol, depuis sa genèse dans les premiers documents du droit de la guerre moderne, conventions de La Haye et tribunaux militaires après la Seconde Guerre Mondiale, en passant par les contributions matérielles et procédurales des tribunaux pénaux ad hoc à l'ex-Yougoslavie et au Rwanda, jusqu'à atteindre le Statut de Rome de la Cour Pénale Internationale (CPI). Enfin, le cas de Jean Pierre Bemba Gombo, récemment jugé par la CPI, sera analysé, ainsi que les apports et revers que l'on peut observer dans ce procès pour le développement de la jurisprudence internationale en la matière.

Mots-clés: crimes sexuels, droit pénal international, Cour Pénale Internationale, Bemba Gombo, justice. 


\section{INTRODUÇÃO}

Os atos de violência sexual, especialmente a violação, ${ }^{1}$ têm sido uma característica dos conflitos armados durante toda a história. Muitas vezes, a violência sexual em tempo de guerra não é apenas um subproduto desta, mas uma política planejada e direcionada pelas partes no conflito. Nesses casos, considera-se a violência como uma verdadeira "arma de guerra", ${ }^{2}$ fazendo com que os abusos sexuais sejam difundidos e orquestrados de forma sistemática e massiva. A impunidade de cometer abusos sexuais sem medo de consequências foi por muito tempo considerada um dos despojos da guerra.

Apesar da ocorrência de crimes sexuais ao longo dos séculos, a tutela desses crimes no âmbito do direito internacional penal é relativamente recente. Apesar da importância dos Tribunais de Nuremberg e de Tóquio para o julgamento internacional de criminosos de guerra, a previsão de violação como crime de guerra foi adotada em grande medida apenas no início da década de 1990, após os conflitos na Bósnia-Herzegovina e Ruanda, quando as atrocidades generalizadas fomentaram a criação do Tribunal Penal Internacional para a Antiga Iugoslávia (TPIY) e do Tribunal Penal Internacional para Ruanda (TPIR).

Os estatutos e a jurisprudência desses tribunais ad hoc exerceram um papel fundamental na prossecução e julgamento dos crimes sexuais, sobretudo no tocante ao reconhecimento da violência sexual durante conflitos armados como crimes under international law, o que serviu de fundamento às disposições do Estatuto de Roma sobre o tema.

Nesse sentido, a criação do Tribunal Penal Internacional ocupa uma posição de destaque para a proteção multinível dos direitos humanos, considerada a incidência simultânea e complementar de diversos ordenamentos

1 "Violação" é o termo mais utilizado em Portugal, enquanto utiliza-se o termo "estupro" no Brasil. Como a investigação foi desenvolvida durante o Doutoramento na Universidade de Coimbra, preferiu-se utilizar o termo "violação". Para os efeitos do presente trabalho, são termos sinônimos e intercambiáveis.

2 Para maiores desenvolvimentos sobre a atuação analítica, epistemológica e ontológica que a "violação como arma de guerra" assume no direito internacional, vide Buss, Doris, "Rethinking Rape as a Weapon of War”, Feminist Legal Studies, vol. 17, núm. 2, 2009, pp. 145-163. 
jurídicos para a proteção dos direitos humanos. Positivados em catálogos diferentes, os mesmos direitos possuem meios de tutela específicos, e sujeitos à competência de diferentes tribunais, resultando numa proteção em nível nacional, regional e global. ${ }^{3}$

Este trabalho objetiva analisar, por meio de investigação bibliográfica e jurisprudencial, a evolução do tratamento conferido pelo direito internacional penal aos crimes de natureza sexual, em especial à violação. Dito de outro modo, o caminho que foi percorrido pela comunidade internacional para considerar a violência sexual não mais um "efeito colateral" da guerra, mas um crime internacional que, a depender das circunstâncias e do preenchimento de certos requisitos, pode configurar-se como crime de genocídio, crime de guerra, ou crime contra a humanidade.

Para isso, a primeira parte do trabalho consiste em analisar de que modo a jurisdição penal internacional, em particular a jurisdição do Tribunal Penal Internacional, contribui para a proteção multinível dos direitos humanos. Em seguida, a pesquisa examinará a evolução histórica dos crimes sexuais no ordenamento jurídico internacional, desde a sua gênese nos primeiros documentos do moderno direito de guerra, passando pelas convenções de Haia e pelos tribunais militares pós-Segunda Guerra, até chegar aos tribunais penais ad hoc para antiga Iugoslávia e Ruanda, considerando, neste ponto, os desenvolvimentos substantivos e procedimentais que esses tribunais trouxeram ao atual ordenamento, consubstanciado no Estatuto de Roma do Tribunal Penal Internacional. A terceira parte é dedicada à análise pormenorizada do Estatuto de Roma no tocante aos crimes sexuais, particularmente o crime de violação. Por fim, analisar-se-á o caso Jean Pierre Bemba Gombo, julgado em 2018 pelo Tribunal Penal Internacional, primeiro caso em que o TPI veio a considerar acusações baseadas fundamentalmente no cometimento de crimes de natureza sexual. Enquanto o julgamento desse caso se baseia no trabalho de outros tribunais, notadamente o TPIY e TPIR, certos aspectos são, no entanto, distintos e emblemáticos, em especial por ter havido uma condenação unânime em primeira instância, e absolvição em sede de apelação.

3 Souza, Jefferson Lima de, "O diálogo entre o Tribunal Constitucional Português e o Tribunal Europeu dos Direitos do Homem e seu impacto na proteção dos direitos fundamentais", em Martins, Ana Maria Guerrra (coord.), A proteção multinível dos direitos fundamentais: estudos sobre diálogo judicial, Lisboa, AAFDL, 2019, pp. 15 e ss. 


\section{PROTEÇÃO MULTINÍVEL DOS DIREITOS ETRIBUNAL PENAL INTERNACIONAL}

\section{Humanização do direito internacional}

O direito internacional tem passado por uma série de transformações. Especialmente após a segunda metade do século $\mathrm{XX}$, temos presenciado o desenvolvimento de um direito internacional, outrora predominantemente interestatal, voltado a regular os direitos e deveres recíprocos dos Estados, para um direito dirigido fortemente para os interesses da "humanidade", dando origem a instituições e organismos que interferem diretamente com as pessoas singulares para proteger e garantir valores humanos superiores.

Apesar de os primeiros passos rumo à humanização do direito internacional terem sido dados após o fim da primeira guerra mundial, através do direito humanitário, do surgimento da Liga das Nações e da Organização Internacional do Trabalho, os fundamentos de uma nova ordem jurídica internacional, baseada em propósitos e princípios centrados no indivíduo, foram estabelecidos com a Carta das Nações Unidas em 1945, ao fim da segunda grande guerra. O preâmbulo da Carta reafirma a "fé nos direitos fundamentais do homem, na dignidade e no valor do ser humano, na igualdade de direito dos homens e das mulheres", e estabelece a promoção dos direitos humanos e das liberdades fundamentais como um dos quatro propósitos da Organização das Nações Unidas (artigo 1.3). ${ }^{5}$ A partir de 1945, resta claro que os direitos humanos não poderiam mais ser caracterizados como uma questão doméstica, escondida pelo véu da soberania do Estado. ${ }^{6}$

No entanto, essa visão dos direitos humanos não resultou na sua imediata elevação à qualidade de normas fundamentais da ordem jurídica internacio-

4 Paulus, Andreas, "Do direito dos Estados ao direito da humanidade? A instituição de um Tribunal Penal Internacional e o desenvolvimento do Direito Internacional”, Direito Penal Internacional para a Proteção dos Direitos Humanos, Lisboa, Fim de Século Edições, 2003, p. 79.

5 Outras disposições da Carta contendo referências aos direitos humanos são: artigos 13 (1) (b), 55 (c), 62 (2), 68 e 76 (c)

6 Joseph, Sarah e Kyriakakis, Joanna, "The United Nations and Human Rights", em Joseph, Sarah e McBeth, Adam (eds.), Research Handbook on International Human Rights Law, Cheltenham, Edward Elger, 2010, p. 1. 
nal, tendo aberto um processo evolutivo de definição de standards universais de proteção. ${ }^{7}$ A Declaração Universal dos Direitos Humanos ocupa uma posição central nessa nova arquitetura normativa global, configurando a sua publicação a primeira vez que a comunidade internacional, composta pelas nações soberanas do mundo, declarou um conjunto de direitos e liberdades fundamentais aos quais todos os seres humanos têm direito.

Seguindo o processo evolutivo do direito internacional, após a Carta da ONU e a Declaração Universal, verificou-se na agenda internacional a necessidade de estabelecimento de um sistema de tratados multilaterais com força jurídica vinculante, através dos quais se estipulariam padrões incondicionais, absolutos e categóricos de conduta para os Estados, ${ }^{8} \mathrm{Com}$ o objetivo de garantir de forma mais efetiva o exercício dos direitos e liberdades fundamentais. Em 1966 são adotados o Pacto Internacional sobre os Direitos Civis e Políticos (PIDCP) e o Pacto Internacional de Direitos Econômicos, Sociais e Culturais (PIDESC). Os mesmos incorporam, concretizam e até ampliam os direitos contidos na Declaração Universal, e criam obrigações erga omnes de respeito pelos direitos humanos. Do advento desses tratados, inúmeras outras declarações e convenções foram elaboradas sob os auspícios das Nações Unidas, no exercício de sua competência normativa (standard-setting) em matéria de direitos humanos. ${ }^{9}$

Ao lado do sistema normativo global, surgem os sistemas regionais de proteção dos direitos humanos, nomeadamente na Europa, América e Áfri$\mathrm{ca}$, regidos por instrumentos normativos e sistemas institucionais próprios. Como leciona Flávia Piovesan, “ao adotar o valor da primazia da pessoa humana, estes sistemas se complementam, somando-se ao sistema nacional de proteção, a fim de proporcionar a maior efetividade possível na tutela e promoção de direitos fundamentais". ${ }^{10}$

7 Machado, Jónatas, Direito internacional: do paradigma clássico ao pós-11 de setembro, 3a ed., Coimbra, Coimbra Editora, 2003, pp. 273 e ss.

8 Ibidem, p. 275.

9 Dentre o vasto número de convenções em vigor, podemos destacar a Convenção sobre Genocídio de 1948, a Convenção sobre Refugiados de 1951, com seu Protocolo de 1967, a Convenção sobre a Eliminação da Discriminação Racial de 1965, e a Convenção sobre os Direitos da Criança de 1989.

10 Piovesan, Flávia e Kamimura, Akemi, "Proteção internacional à diversidade sexual e combate à violência e discriminação baseadas na orientação sexual e identidade de gênero", Anuario de Derecho Público, Santiago de Chile, núm. 1, 2017, p. 180. 
A condição dos indivíduos como detentores de personalidade jurídica internacional é hoje uma realidade inegável, e pode ser constatada, como vimos, pela multiplicação dos tratados internacionais de proteção dos direitos humanos, que permitem, expressamente, o ingresso direto dos indivíduos às instâncias internacionais, bem como a possibilidade que indivíduos sejam demandados perante cortes internacionais, como é o caso do Tribunal Penal Internacional.

Com efeito, a instituição do Tribunal Penal Internacional pelo Estatuto de Roma constitui a mais recente expressão normativa e institucional do desenvolvimento direito internacional que estamos a referir, nomeadamente a mudança de paradigma e estrutura no sentido da proteção e garantia dos direitos humanos.

\section{Realização dos direitos humanos pela justiça penal internacional}

Embora o Tribunal Penal Internacional não seja um tribunal de direitos humanos stricto sensu, sua criação possui um grande significado para a proteção global —e multinível — dos direitos humanos.

Os tribunais militares de Nuremberg e Tóquio, e mais recentemente os tribunais para Iugoslávia e Ruanda, contribuíram para o estabelecimento da legitimidade da comunidade internacional para investigar, processar e julgar os acusados de crimes que põem em risco a paz e a sobrevivência dessa própria comunidade. Estabelecida a legitimidade, e presentes as noções que levaram ao cenário do novo direito internacional, ou seja, de soberania limitada dos Estados em face dos interesses comuns da humanidade, surge o Tribunal Penal Internacional. ${ }^{11}$

O TPI é uma instituição judicial permanente criada para acabar com a impunidade dos crimes mais graves de interesse internacional, nomeadamente genocídio, crimes contra a humanidade, crimes de guerra e crime de agressão. Essas quatro categorias de ofensas estipuladas no Estatuto do TPI se relacionam fortemente com as normas internacionais de direitos

11 Steiner, Sylvia, "Discurso de abertura”, em Albuquerque, Paulo Pinto e Silva, João Miguel (orgs.), O Tribunal Penal Internacional e a transformação do direito internacional, Lisboa, Universidade Católica Editora, 2006, p. 12. 
humanos, na medida que os atos proibidos pelo Estatuto de Roma dizem respeito, em grande parte, aos direitos humanos mais fundamentais, normas peremptórias do direito internacional, como o direito à vida e a proibição de tortura, além de ofensas que afetam particularmente mulheres e crianças, e inúmeras outras conexões com direitos humanos específicos, por exemplo, a proibição de discriminação racial e a liberdade de movimento.

Além da ligação entre o conteúdo dos crimes de competência do TPI e os direitos humanos, importa considerar a correspondência entre a justificação de existência dos mecanismos internacionais de direitos humanos e de justiça criminal. Nesse sentido, Hans-Peter Kaul ${ }^{12}$ aponta para a obrigação tripla (threefold obligation) que os Estados têm em relação aos direitos humanos. Em primeiro lugar, os Estados devem abster-se de qualquer violação; segundo, os Estados têm a obrigação de proteger indivíduos e grupos contra violações dos direitos humanos, o que implica, por exemplo, no dever de criminalizar certos comportamentos, de investigar e processar abusos e de responsabilizar os autores; terceiro, é dever dos Estados adotar medidas positivas para materialização dos direitos humanos.

Cumpre destacar que os sistemas internacionais de direitos humanos não foram concebidos para substituir os Estados como garantidores dos direitos e garantias individuais, mas para servir de camadas ou níveis sobressalentes de supervisão, proteção e responsabilização. Essa é a mesma rationale de justificação do direito internacional penal. Com efeito, o TPI não substitui os sistemas de justiça nacionais, antes, incentiva e estimula a primazia da jurisdição interna dos Estados. Continua da responsabilidade primária do sistema de justiça doméstico o exercício da jurisdição criminal sobre os crimes mais graves da ordem internacional. Diante, porém, das recorrentes atrocidades em que os sistemas jurídicos nacionais mostram-se relutantes ou incapazes de responder, o TPI é capaz — frise-se, em caráter complementar - de constituir a última instância que pode julgar os indivíduos suspeitos de serem responsáveis pelos crimes.

12 Kaul, Hans Peter, "The Protection of Human Rights through the International Criminal Court as a Contribution to Constitutionalization and Nation-Building”, Human RightsInternational Criminal Court, The Hague, 2011. Disponível em: https: / /www.icc-cpi.int/NR/ rdonlyres/33E021F0-8672-4210-8170-790E380A1AA1/282948/FINAL_Speech_Panel3_ICC_ Features_Challenges.pdf. 
Sem prejuízo de analisarmos em detalhes, na próxima sessão, as inovações, em termos substantivos e processuais, do Estatuto de Roma, pode-se afirmar que o TPI é o herdeiro direto dos Tribunais estabelecidos em Nuremberg e Tóquio, que estabeleceram o princípio da responsabilidade de todos os indivíduos sob o direito penal por atrocidades em massa, ainda que sejam representantes do alto escalão do estado ou de seu aparato militar. Estabelecido de forma permanente, com jurisdição não retroativa, e um sistema procedimental pré-estabelecido, no qual são assegurados os princípios da publicidade, da paridade de armas, da ampla defesa e do contraditório, o TPI representa, para alguns autores, a maior transformação havida nas últimas décadas em termos de proteção internacional de direitos individuais, um passo adiante à criação dos tribunais de direitos humanos, já que agora não somente os Estados, mas as pessoas individualmente, são chamados a prestar contas perante a comunidade internacional. ${ }^{13}$

\section{CRIMES SEXUAIS NO DIREITO INTERNACIONAL PENAL: EVOLUÇ̃̃O HISTÓRICA}

\section{Código Lieber e convenções de Haia}

O primeiro documento que proibiu, de forma expressa, a prática da violação em tempos de guerra foi o Código Lieber de 1863. ${ }^{14}$ Este Código, por reconhecer o "caráter sagrado das relações domésticas", estabelece a pena de morte para os perpetradores da violação e ainda confere ao superior o direito de matar o agente de tais atos quando contrários a uma determinada ordem (arts. 44 e 47).

13 Steiner, Sylvia, op. cit., p. 14.

14 O Lieber Code tem um importante valor no moderno direito de guerra, em virtude de constituir a primeira tentativa de estabelecer, por escrito, um conjunto de regras que dizem respeito aos usos e costumes de guerra e impô-las a um exército durante uma batalha. Apesar disso, tinha como objetivo somente prescrever um conjunto de regulações à conduta dos Soldados dos Estados Unidos (“União' ou Norte”) que lutavam na Guerra Civil Americana contra os Estados Confederados da América ("Confederação" ou "Sul”), e portanto não tinha status de tratado. 
As convenções de Haia de 1899 e 1907 codificaram as regras atinentes à guerra existentes até então. Porém, não houve nenhuma referência expressa à violação ou outra forma de violência sexual. Os crimes sexuais ficaram vinculados ao respeito pela "honra e direitos da família". ${ }^{15}$

Ressalta-se que o preâmbulo da convenção previa que, na ausência de regras codificadas, os beligerantes deveriam ser regidos pelos princípios do direito das nações, das leis da humanidade e pelos ditames da consciência pública. Fraciah Njoroge entende que essa provisão proibia implicitamente a violação na condução dos conflitos, já que a violência sexual fere a dignidade humana e a honra da família, sendo, portanto, contra os ditames da consciência pública. ${ }^{16}$

\section{Tribunais Pós-Segunda Guerra e Convenções de Genebra}

Após a Segunda Guerra Mundial, foram criados o Tribunal Militar Internacional de Nuremberg (1945) e posteriormente o Tribunal Militar Internacional de Tóquio (1946), resultados dos esforços da comunidade internacional para julgamento dos acusados de crimes contra a paz, crimes contra a humanidade e crimes de guerra cometidos durante o período do conflito. Nas cartas de ambos os tribunais não havia qualquer referência ao crime de violação, ${ }^{17}$ apesar de considerar-se possível a punição de abusos de caráter sexual pelo recurso à cláusula de "outros atos desumanos", presente nos dois Estatutos. ${ }^{18}$ Ressalta-se que em 20 de dezembro de 1945 as potências aliadas que ocupavam o território alemão aprovaram a Lei n. 10 do Conse-

15 International Conferences (The Hague), Hague Convention (IV) Respecting the Laws and Customs of War on Land and Its Annex: Regulations Concerning the Laws and Customs of War on Land, 18 October 1907, Article 46. Disponível em: https: //ihl-databases.icrc.org/ ihl/INTRO/ 195.

16 Njoroge, Fraciah, "Evolution of Rape as a War Crime and a Crime against Humanity", SSRN, 2016. Disponível em: https: / /ssrn.com/abstract $=2813970$.

17 United Nations, Charter of the International Military Tribunal-Annex to the Agreement for the Prosecution and Punishment of the Major War Criminals of the European Axis (London Agreement), 8 August 1945, Article 60.

18 Fidalgo, Sofia, “Os crimes sexuais no direito internacional penal”, Boletim da Faculdade de Direito, Coimbra, vol. 83, 2007, p. 642. 
lho de Controle, que incluiu a violação entre os crimes contra a humanidade previstos na Carta de Nuremberg, e requereu a cada uma das potências que julgassem o cometimento desse crime. ${ }^{19}$

Apesar desse avanço, em Nuremberg os julgamentos ignoraram amplamente os atos de violência sexual cometidos, embora soldados do eixo e das forças aliadas tenham sido acusados do cometimento de violação contra civis durante o conflito. Há quem diga, inclusive, que esta é a verdadeira razão de o crime de violação não ter sido investigado pelo Tribunal de Nuremberg, "não porque os alemães não tenham cometido violações, mas porque as forças Aliadas, sobretudo os Russos e as f orças Marroquinas sob controle francês, também cometeram inúmeras violações". ${ }^{20}$

Em Tóquio, a despeito do fato de não haver referência à violência sexual em sua Carta, o Tribunal decidiu que os atos de violência sexual constituíam “crimes de guerra costumeiros" previstos no artigo 5o., alínea b, e, assim, condenou criminosos de guerra pelo delito de violação e prostituição forçada. No caso específico, havia evidências de violaçãoe prostituição forçada de mulheres chinesas por soldados japoneses, especialmente durante o episódio que ficou conhecido como "rape of Nanking", em que soldados japoneses invadiram a cidade de Nanking e violaram aproximadamente vinte mil mulheres e crianças como estratégia de dominação. Este foi, portanto, o primeiro tribunal internacional a processar e condenar os perpetradores de violência sexual em um conflito armado.

Conforme aduz Quitter, os julgamentos de Nuremberg e de Tóquio "prepararam o terreno" para o julgamento internacional de criminosos de guerra por homicídio, genocídio, crimes contra a humanidade e outros crimes de guerra, mas os crimes sexuais ainda não eram vistos como crimes de caráter internacional. ${ }^{21}$ Somente quarenta e cinco anos mais tarde, através da ação do Tribunal Penal Internacional para a Antiga Iugoslávia, os atos de violência sexual durante conflitos armados foram processados como crime de guerra, momento histórico que passamos a analisar adiante.

19 Control Council Law No. 10 Punishment of Persons Guilty of War Crimes, Crimes against Peace and Against Humanity, December 20, 1945. Article II(c).

20 Fidalgo, Sofia, op. cit., p. 642.

21 Quitter, Bridget, "Rape as a War Crime--Prosecution of Sexual Violence in the International Community”, SSRN, 2013. Disponível em: https: / /ssrn.com/abstract $=2498208$. 
Há de se destacar, ainda, que a IV Convenção de Genebra de 1949, Relativa à Proteção das Pessoas Civis em Tempos de Guerra ${ }^{22}$, refere expressamente a violação em seu artigo 27 , afirmando que "as mulheres serão especialmente protegidas contra qualquer ataque à sua honra, particularmente contra a violação, a prostituição forçada ou qualquer forma de atentado ao seu pudor”. Percebe-se da leitura deste e dos demais artigos da Convenção, e dos seus Protocolos Adicionais de 1977, que a proteção da mulher contra abusos sexuais continua ligada à sua honra e pudor; e os crimes sexuais não constam expressamente da lista das violações graves da Convenção, submetidas à jurisdição universal. ${ }^{23}$

\section{Tribunais penais internacionais ad hoc} para antiga Iugoslávia e para Ruana

Os TPIY e TPIR trouxeram grandes contribuições ao reconhecimento e prossecução da violência sexual no âmbito internacional. ${ }^{24}$ Para alguns autores, a ação desses tribunais marca o início do fim da impunidade dos crimes sexuais no direito internacional. ${ }^{25}$

O TPIY foi a primeira corte internacional a reconhecer a violação como crime contra a humanidade, ${ }^{26}$ além de ser a primeira corte a condenar um indivíduo com base nessa tipificação. O Estatuto do TPIY não prevê expressamente a violação como crime de guerra, mas, ainda assim, o Tribunal afirmou em diversas situações que a violência sexual deve ser considerada uma "grave violação das leis e costumes de guerra”. Além disso, o Estatuto do Tribunal,

22 IV Geneva Convention Relative to the Protection of Civilian Persons in Time of War of 12 august 1949. Disponível em: http: / / www.redcross.org/humanityinwar/geneva-convention-iv -on-civilians-1949.

23 Artigos 146 e 147 da IV Convenção de Genebra.

24 O TPIY foi estabelecido em 1993 pela Resolução 82723 do Conselho de Segurança das Nações Unidas, de acordo com o artigo 39 do capítulo VII da Carta das Nações Unidas, que autoriza o Conselho a responder a "qualquer ameaça à paz". O TPIR foi estabelecido em 1994 com base no mesmo capítulo.

25 Fidalgo, Sofia, op. cit., p. 644; Fitzgerald, Kate, "Problems of Prosecution and Adjudication of Rape and other Sexual Assaults under International Law”, European Journal of International Law, vol. 8, núm. 4, 1997, pp. 638-663.

26 Estatuto do TPIY, artigo 5o., alínea g. 
ao considerar os "graves atentados contra a integridade física ou psíquica do grupo" como uma das possiblidades de configuração do crime de genocídio, permite, a partir de uma interpretação extensiva, que a violência sexual seja enquadrada como possível ato constitutivo de genocídio, desde que cometida nas circunstâncias adequadas, ou seja, com a intenção de destruir total ou parcialmente um grupo racial, étnico ou religioso.

O Estatuto do TPIR trata a violação como crime contra a humanidade. ${ }^{27}$ Além disso, estabelece que o Tribunal tem competência para julgar as pessoas que tenham violado ou que tenham ordenado a prática de violações graves ao artigo 3o. comum às Convenções de Genebra, de 12 de agosto de 1949, para a Proteção das Vítimas de Guerra, e ao Segundo Protocolo Adicional, de 8 de junho de 1977. Dentre estas violações, incluem-se: ultraje à dignidade da pessoa, nomeadamente os tratamentos humilhantes e degradantes, violação, prostituição e qualquer outra forma indecente de ofensa (artigo 4o., al. e).

As diferenças mais significativas nas interpretações e julgamentos desses dois Tribunais dizem respeito à definição de violação.

O caso Prosecutor vs Tadic, ${ }^{28}$ primeiro julgamento do TPIY e, portanto, o primeiro caso julgado por um Tribunal Internacional Penal pós Nuremberg e Tóquio, envolvia, entre outras acusações, o cometimento massivo de violações contra homens e mulheres por parte de Tadic, guarda em uma prisão da Sérvia. No entanto, ao final do julgamento as acusações de violência sexual foram retiradas, dadas as inconsistências das testemunhas.

O Caso Prosecutor vs. Akayesu, ${ }^{29}$ julgado pelo TPIR, envolveu o burgomestre da comuna de Taba, Jean Paul Akayesu, e sua participação no massacre de quase todos os tutsis residentes no distrito. Ele foi acusado de promover e apoiar atos de violência sexual contra as mulheres tutsis, como parte do processo de extermínio dos tutsis e uma forma de evitar o nascimento de outros membros do grupo.

Através desse caso, o TPIR foi o primeiro tribunal internacional a i) condenar um indivíduo por crime de genocídio; ii) considerar que a violação de mulheres é um ato constitutivo de genocídio; iii) considerar que a violência

27 Estatuto do TPIR, artigo 3o., alínea g.

28 International Criminal Court, Prosecutor v.Tadic, Case No. IT-94-1-T, de 7 de maio de 1997.

29 International Criminal Court, Prosecutor v. Akayesu, Case No. ICTR-96-4-T, de 2 de setembro de 1998 . 
sexual quando realizada como parte de um ataque, generalizado ou sistemático, contra a população civil, por motivos discriminatórios, como observou-se no caso concreto, constitui, por si mesma, crime contra a humanidade. ${ }^{30}$

O caso Akayesu foi particularmente inovador porque o Tribunal teve de definir a violação a nível internacional, vez que nenhuma definição tinha sido reconhecida até antes do julgamento. Assim, o Tribunal definiu violação como “a penetração física de natureza sexual cometida de forma coerciva”, e acrescentou que "a violência sexual não se limita à invasão física do corpo humano, pode incluir atos que não envolvem penetração ou mesmo contato físico”.

O caso Prosecutor vs. Mucic ${ }^{31}$ é um dos mais conhecidos que veio a ser julgado pelo TPIY, porque envolveu a acusação de quatro réus pelas atrocidades cometidas no campo de prisão Celebici. Esse caso é juridicamente significativo para o escopo do presente trabalho pois a Corte sustentou que a violação e violência sexual podem constituir atos de tortura, desde que cumpridos os seus requisitos de configuração, ${ }^{32}$ pois trata-se de um "ato desprezível que atinge o âmago da dignidade humana”. Ademais, ao julgar os atos de violência sexual cometidos na prisão, a Corte precisava adotar uma definição para o crime de violação, e assim o fez referenciando a decisão do TPIR no caso Akayesu, definindo a violação como "uma invasão física de natureza sexual, cometida em uma pessoa sob circunstâncias coercivas".

O caso Prosecutor vs. Furundzija, ${ }^{33}$ julgado pelo TPIY, teve como objeto as acusações contra Anto Furundzija, comandante dos "Jokers", uma unidade

30 Ferreira de Almeida, Francisco, Os crimes contra a humanidade no actual direito internacional penal, dissertação para doutoramento em Ciências Jurídico-Políticas pela Faculdade de Direito da Universidade de Coimbra, Coimbra, 2007, p. 343.

31 International Criminal Court, Prosecutor v. Zejnic Delalic, Zdravko Mucic, Hazim Delic and Esan Landzo. Case No. IT-96-21, de 16 de novembro de 1998.

32 Artigo 1o. da Convenção contra a Tortura e outros Tratamentos ou Penas Cruéis, Desumanos ou Degradantes (1984): O termo "tortura” designa qualquer ato pelo qual dores ou sofrimentos agudos, físicos ou mentais, são infligidos intencionalmente a uma pessoa a fim de obter, dela ou de uma terceira pessoa, informações ou confissões; de castigá-la por ato que ela ou uma terceira pessoa tenha cometido ou seja suspeita de ter cometido; de intimidar ou coagir esta pessoa ou outras pessoas; ou por qualquer motivo baseado em discriminação de qualquer natureza; quando tais dores ou sofrimentos são infligidos por um funcionário público ou outra pessoa no exercício de funções públicas, ou por sua instigação, ou com o seu consentimento ou aquiescência.

33 Prosecutor v. Furundzija, Case Nº. IT-95-17/1-T, de 10 de dezembro de 1998. 
especial do Conselho de Defesa Croata, que lutou contra o exército da Sérvia. Ele foi acusado de ter submetido a população civil, especificamente muçulmanos sérvios, a diversas hostilidades, como atos de tortura, violência sexual e outros abusos físicos e psíquicos.

A sentença desse caso ocupa um lugar de destaque no tema da violência sexual porque, ao definir a violação, a Corte se distanciou do precedente em Akayesu e definiu o crime de uma forma mais detalhada e precisa, estabelecendo que a violação consiste: "i) na penetração sexual, por insignificante que seja: a) da vagina ou ânus da vítima pelo pênis do agente ou por qualquer outro objeto usado pelo agente; ou b) da boca da vítima pelo pênis do agente; ii) mediante coação, força ou ameaça de uso da força contra a vítima ou contra uma terceira pessoa”.

Diferentemente da definição adotada nos casos Mucic e Akayesu, o Tribunal centrou-se nos aspectos físicos do ato sexual e enumerou de forma precisa os fatos concretos que podem motivar uma violação, mencionando tanto as partes do corpo afetadas, como os instrumentos do crime. Quitter considera essa nova definição um retrocesso, pois não fornece recursos de proteção às vítimas de violência sexual cometida sem penetração, ao contrário do que poderia ocorrer sob as definições anteriores. ${ }^{34}$

O caso Prosecutor vs. Kunarac, Kovac eVukovic, ${ }^{35}$ julgado pelo TPIY, foi o primeiro no Direito Internacional Penal em que as acusações envolviam apenas crimes de natureza sexual. O caso em comento envolveu três acusados que participaram da invasão do município de Foca em abril de 1994. Os soldados sérvios dividiram a população entre homens e mulheres; os homens foram enviados a diversas prisões, enquanto as mulheres e crianças foram enclausuradas, primeiro no ginásio da escola da cidade, e depois no estádio Partizan Sports Hall. As mulheres foram vítimas de atrocidades massivas, sobretudo de natureza sexual. Os acusados foram condenados pelo cometimento de atos de violência sexual enquanto violações de leis ou costumes de guerra, assim como crimes contra a humanidade.

O Tribunal decidiu voltar a utilizar a definição de violação do caso Akaye$s u$, pois verificou que a definição proporcionada no caso Furundzija era demasiado restritiva, ao atrelar a ausência do consentimento da vítima à

34 Quitter, Bridget, op. cit., p. 12.

35 International Criminal Court, Prosecutor vs. Kunarac, Kovac eVukovic, Nº. IT-96-23, de 22 de fevereiro de 2011. 
coação, uso ou ameaça de uso da força. Para o Tribunal, a falta de consentimento pode extrair-se de circunstâncias para além da força, como extrema pressão psicológica, enfermidade física ou mental, menoridade, entre outros. Portanto, substitui-se o elemento "coação, força ou ameaça de uso da força" pelo elemento "ausência de consentimento". Isso significa que o uso ou ameaça de uso da força passa a ser não mais um elemento consubstancial da natureza da violação, apenas uma das formas pelas quais se pode viciar o consentimento da vítima, o que representou um grande avanço na proteção dos direitos das vítimas desse tipo de violência.

Importante perceber que, se tratando de um contexto generalizado de violência e ameaças, tal como ocorre em grande parte dos conflitos armados, é possível que a vítima tenha sido compelida a consentir devido às circunstâncias do contexto em questão. Assim, o consentimento para manter relações sexuais deve ser "absolutamente livre e voluntário". Obviamente, esse elemento subjetivo (mens rea) é difícil de ser provado, pois o autor pode alegar que considerava que a vítima consentia legitimamente a ter relações sexuais com ele. ${ }^{36}$

A introdução do elemento "ausência de consentimento" representa, ademais, a mudança no bem jurídico protegido pelo ordenamento jurídico internacional no crime de violação. Até então, considerava-se que o crime visava à proteção da integridade física e a dignidade humana. A partir desse caso, com a "nova" definição de violação, percebe-se que o bem jurídico que o direito internacional busca proteger é a liberdade e autodeterminação sexual, que passa a ser, portanto, um bem jurídico da humanidade, supra individual, cuja proteção é essencial à comunidade internacional. ${ }^{37}$

Ainda na seara das contribuições dos TPIY e TPIR, merece destaque a inovação no plano processual trazida pelo artigo 96 do Regulamento de Procedimento e de Prova do TPIY, que estabelece regras de apreciação da prova em matéria de crimes sexuais. De acordo com esse artigo, que não contava com nenhum precedente similar antes da sua adoção: i) não se exige a corroboração do testemunho da vítima por outras testemunhas; ii) o consentimento da vítima não será admitido como defesa se (a) a vítima tiver

36 Zorrila, Maider, La Corte Penal Internacional ante el crimen de violencia sexual, Bilbao, Universidad de Deusto-Instituto de Derechos Humanos, 2005, p. 42.

37 Fidalgo, Sofia, op. cit., p. 648. 
sido submetida, ameaçada, ou tenha motivos para temer violência, coação, detenção ou opressão psicológica, ou (b) razoavelmente se acredite que se a vítima não foi submetida a essas hipóteses, outra pessoa pode ter sido ou vir a ser; iii) antes de ser admitida a prova do consentimento da vítima, o acusado deve satisfazer à Câmara de Julgamento que as provas são relevantes e credíveis; iv) O comportamento sexual prévio da vítima não será admitido como prova.

O TPIY também prestou especial atenção à proteção e apoio das vítimas. Nesse sentido, estabeleceu uma Unidade de Vítimas e Testemunhas, constituída por pessoal qualificado para recomendar medidas de proteção e prestar aconselhamento para vítimas e testemunhas. Outras inovações foram: adotou-se a regra da não divulgação de nomes e outras informações das vítimas em registos públicos; o Tribunal garantiu que as vítimas não pudessem ser vistas na galeria pública; conferiu-lhes a opção de apresentar provas em sessões fechadas. Muitas dessas inovações foram posteriormente adotadas pelo Tribunal Penal Internacional. ${ }^{38}$

Graças aos Estatutos e decisões do TPIY e TPIR, foi possível, pela primeira vez, definir o crime de violação no âmbito internacional; conseguiu-se distinguir de forma mais detalhada o crime de violação de outros abusos de natureza sexual; institui-se a violação como crime contra a humanidade, crime de guerra e genocídio, dependendo das circunstâncias do cometimento do ato; e adotou-se uma série de medidas protetivas às vítimas de abusos sexuais. Ainda que sujeita a limitações temporais e espaciais muito restritivas, estes Tribunais tiveram uma influência importante à criação do Tribunal Penal Internacional, que, a princípio, compartilha objetivos com os dos tribunais ad hoc, mas se diferencia fundamentalmente destes por conta da permanência do seu mandato. ${ }^{39}$

\section{Crime de violação no Estatuto de Roma}

O nascimento do Tribunal Penal Internacional (TPI) representou um marco de enorme significado para a comunidade internacional. Desde $1 \mathrm{de}$

\footnotetext{
38 Manning, Colin, Development of International Criminal Law of Sexual Violence, SSRN, 2016. Disponível em: https: / /ssrn.com/abstract $=2728700$.
}

39 Zorrila, Maider, op. cit., pg. 49. 
julho de 2002, quando alcançado o número suficiente de ratificações (60) do Estatuto de Roma, o Tribunal está habilitado para processar e julgar os crimes de genocídio, crimes de guerra, crimes contra a humanidade e crimes de agressão ocorridos posteriormente àquela data. ${ }^{40}$

O Estatuto desvincula definitivamente os crimes sexuais de concepções ligadas à honra e à dignidade da mulher e da família (note-se que os crimes sexuais como crimes de guerra são tipificados separadamente dos ultrajes à dignidade da pessoa), e também consolida o fato que os crimes sexuais podem constituir um crime de genocídio, um crime de guerra ou um crime contra a humanidade, a depender das circunstâncias presentes em cada caso concreto. ${ }^{41}$

Enquadrar-se-á a violência sexual como elemento do crime de genocídio quando praticada com intenção de destruir, no todo ou em parte, um grupo nacional, étnico, racial ou religioso, nos termos do artigo 6o. do Estatuto. Vale mencionar que tal como está tipificado no Estatuto de Roma, não há referência expressa a atos de violência sexual na descrição do crime de genocídio, tendo sido codificada a cláusula geral "lesões graves à integridade física ou mental de membros do grupo" (artigo 6o. al. b). No entanto, o documento sobre os Elementos dos Crimes, aprovado pela Assembleia dos Estados Partes contém uma nota esclarecendo que a conduta causadora destas lesões "pode incluir, mas não necessariamente se limita a, atos de tortura, violação, violência sexual ou tratamento desumano ou degradante”, restando-se claro, portanto, que os crimes sexuais estarão sob a jurisdição do Tribunal Penal Internacional quando constituírem atos de genocídio.

$\mathrm{O}$ artigo 7o. do Estatuto dispõe que a violência sexual, quando cometida no quadro de um ataque, generalizado ou sistemático, contra qualquer população civil, havendo conhecimento desse ataque, será enquadrada como um crime contra a humanidade. Nesse sentido, o documento sobre os Elementos dos Crimes afirma que os crimes contra a humanidade figuram entre os crimes mais graves que preocupam a comunidade internacional, uma conduta inadmissível ao abrigo do direito internacional geralmente aplicável pelos principais sistemas jurídicos do mundo, exigindo, portanto, a responsabilização penal individual.

40 Ferreira de Almeida, Francisco, Direito internacional público, 2a. ed., Coimbra, Coimbra Editora, 2003, p. 336.

41 Fidalgo, Sofia, op. cit., p. 651. 
É no âmbito dos crimes contra a humanidade que o Estatuto de Roma regula de forma expressa os crimes sexuais, prevendo, pela primeira vez em âmbito internacional, a título exemplificativo, diversas formas de crimes sexuais — violação, escravidão sexual, prostituição forçada, gravidez forçada, esterilização forçada e outras formas de violência.

Para que se compreendam as circunstâncias que implicarão à circunscrição da violência sexual nesta categoria de crime, há de se levar em especial consideração dois elementos necessários à configuração dos crimes contra a humanidade, que dizem respeito ao contexto em que a conduta deve ocorrer: a participação no, e o conhecimento do ataque generalizado ou sistemático contra uma população civil. O elemento que a aponta a necessidade de o perpetrador da conduta criminosa ter a consciência que suas ações fazem parte de um ataque generalizado ou sistemático contra a população civil não significa a exigência de provas de que o autor tinha conhecimento de todas as características do ataque ou os detalhes precisos do plano ou política do Estado ou organização. Além disso, tratando-se de um ataque emergente contra uma população civil, a cláusula de intenção, (mens rea) é satisfeito provando-se que o autor pretendia, com sua conduta, promover tal ataque generalizado ou sistemático.

Os crimes sexuais podem ser configurados também como crimes de guerra, seja em conflitos armados internacionais ou conflitos armados internos, "quando cometidos como parte integrante de um plano ou de uma política ou como parte de uma prática em larga escala”, nos termos do artigo 8o. do Estatuto. Para que a violência sexual constitua um crime de guerra, exige-se ainda que o autor da conduta saiba as circunstâncias factuais que estabelecem a existência de um conflito armado, ainda que não tenha conhecimento se o conflito é internacional ou interno. ${ }^{42}$

No que concerne à violação, de acordo com os Elementos de Crimes, há dois elementos constitutivos que se aplicam para sua configuração como crime de guerra ou crime contra a humanidade: 1) O agressor invadiu o corpo de uma pessoa por conduta que resultou na penetração, por mais leve que fosse, de qualquer parte do corpo da vítima ou do autor com um órgão sexual, ou da abertura anal ou genital da vítima com qualquer objeto

42 "Elements of Crimes. Official Records of the Review Conference of the Rome Statute of the International Criminal Court", Kampala, 31 May-11 June 2010, International Criminal Court publication, $\mathrm{RC} / 11$. 
ou qualquer outra parte do corpo. 2) A invasão foi cometida por força, ou por ameaça de força ou coerção, assim como por medo de violência, coação, detenção, opressão psicológica ou abuso de poder, contra tal pessoa ou outra pessoa, ou por tirar vantagem de um ambiente coercivo, ou a invasão foi cometida contra uma pessoa incapaz de dar o consentimento genuíno. Pode-se afirmar, assim, que o TPI incorporou e consolidou os desenvolvimentos jurídicos conseguidos pelos Tribunais ad hoc que o antecederam.

Apenas a título de exemplo, os Elementos dos Crimes codificaram a compreensão de consentimento desenvolvido no caso Akayesu, especificamente incluindo "ameaça de força ou coerção" e "tirar vantagem de um ambiente coercitivo" na definição do crime de violação. ${ }^{43}$

Fildago destaca, ainda, duas inovações do o Estatuto do TPI em matérias de crimes sexuais. Em primeiro lugar, o Estatuto foi inovador quanto aos órgãos do Tribunal. $\mathrm{O}$ artigo $36^{\circ}$. , n. ${ }^{\circ} 8$, al. b) estatui a "necessidade de assegurar a presença de juízes especializados em determinadas matérias, incluindo, entre outas, a violência contra mulheres ou crianças”. Além disso, no gabinete do procurador deve haver "assessores jurídicos especializados em determinadas áreas, incluindo, entre outras, as da violência sexual” (artigo $42^{\circ}, n^{\circ} 9$ ). Em segundo lugar, no que concerne ao procedimento. $\mathrm{O}$ artigo $54 .^{\circ} \mathrm{n} .{ }^{\circ} 1$, al.b) indica que no inquérito e em toda a sua atuação o "procurador terá em conta os interesses e a situação pessoal das vítimas e das testemunhas, incluindo a idade, o sexo..., a natureza do crime, em particular quando envolva violência sexual”. Além disso, prevê-se expressamente que tratando-se de uma vítima de violência sexual, a audiência pode realizar-se, no todo ou em parte, à porta fechada (artigo 68. ${ }^{\circ}$ n.2).$^{44}$

\section{Avanços e retrocessos do CASO BEMBA GOMBO}

Em 21 de março de 2016, a Terceira Secção de Julgamento do TPI condenou o ex-Vice-Presidente da República Democrática do Congo (RDC) e

43 O próprio Estatuto de Roma foi influenciado pela condenação de Kunarac e enumera a tortura e a violação como crimes contra a humanidade separados. Manning, Colin, op. cit., p. 10 .

44 Fidalgo, Sofia, op. cit., p. 654 e 655. 
líder do Mouvement de libération du Congo (MLC), Jean-Pierre Bemba Gombo, por crimes contra a humanidade e crimes de guerra, inclusive pela prática de crimes sexuais, nomeadamente violação. Os crimes foram cometidos entre 26 de outubro de 2002 e 15 de março de 2003, período em que as tropas de Bemba Gombo realizaram uma intervenção na República Centro-Africana, em apoio ao presidente Ange-Félix Patassé, que à época enfrentava problemas de insurgência no país e pediu a ajuda do MLC.

Em junho de 2018, porém, a Secção de Recursos decidiu absolver Bemba Gombo, por 3-2. Este julgamento é emblemático e significativo por duas razões primordiais: até o julgamento pela secção de recursos, o caso caminhava para constituir o primeiro em que o réu seria condenado por crimes cometidos por seus subordinados, ou seja, a título da "responsabilidade do superior" (command responsibility); e, mais importante, o primeiro julgamento do TPI em que seria prolatada uma sentença condenatória pela prática do crime de violação. ${ }^{45}$

O foco do presente capítulo é examinar criticamente o entendimento do TPI no julgamento de Bemba Gombo, em seus dois momentos cruciais, a decisão da secção de julgamento em 1a. instância e a decisão da secção de recursos, e em que medida esse caso contribuiu ao desenvolvimento da jurisprudência internacional sobre o tema.

\section{Julgamento em primeira instância}

\section{A. Definição de violação}

Até os anos 90, não havia definição do crime de violação no Direito Internacional Penal. Os Tribunais Internacionais que tentaram criar uma definição dos elementos desse crime - como visto, os Tribunais Penais Internacionais para a Antiga Iugoslávia e Ruanda - divergiram especialmente no tocante ao relacionamento entre a força/coerção e o consentimento. ${ }^{46}$

45 Nesse sentido, vale considerar que o julgamento de Katanga (ICC-01/04-01/07), Trial Chamber, 7 March 2014, foi o primeiro caso perante o TPI a incluir acusações de violação e escravidão sexual. Porém, a Câmara de Julgamento decidiu que a violação não se enquadrava no "objetivo comum" dos ataques à vila de Bogoro, e, assim, Katanga foi absolvido das acusações de crimes sexuais.

46 Njoroge, Fraciah, op. cit., p. 9 e ss. 
No caso Kunarac foi adotada uma definição de violação que se baseava no elemento "ausência de consentimento", em substituição à coação ou o uso de força, pelas razões já mencionadas. Porém, alguns questionamentos permaneceram em aberto, no que se refere à adequação de se aplicar uma definição baseada - ainda que de forma atenuada - no consentimento, se estamos tratando de um contexto de crimes de guerra e crimes contra a humanidade. Isso porque a definição de violação pelo direito internacional penal pressupõe um contexto de conflito armado, e, sendo assim, as vítimas estão sob um ataque não-consensual. Isso significa que a própria determinação de competência de um Tribunal Penal Internacional para julgamento desse tipo de crime revela que o ato sexual ocorreu num contexto em que não havia autonomia sexual.

Uma das razões pelas quais o julgamento em sede de 1a. instância em Bemba Gombo é significativo é precisamente porque não emprega uma definição de violação com base no consentimento. ${ }^{47} \mathrm{~A}$ Seç̧ão de Julgamento utilizou a definição de violação prevista no documento Elementos dos Crimes, que por si só não confere um grau elevado de importância ao consentimento. ${ }^{48}$

\section{B. Consequências dos crimes sexuais}

Os Tribunais Penais Internacionais ad hoc refletiram sobre alguns efeitos e consequências da violência sexual sofrida pelas vítimas. Em especial nos casos Mucic e Akayesu, foram destacadas as consequências físicas e psicológicas nos homens e mulheres vítimas de violação. No julgamento de Bemba, as múltiplas consequências das violações massivas perpetradas no conflito são expostas e discutidas de forma detalhada. ${ }^{49}$

Em primeiro lugar, o TPI considerou as lesões físicas agudas e duradouras provocadas nas vítimas, tanto nas mulheres (como lesões permanentes na vagina, pelve, rins, olhos, abdômen, problemas para engravidar) quanto nos homens (diminuição da locomoção e lesões no ânus), sem falar do alto índice de infecção pelo vírus HIV. ${ }^{50}$ Além disso, o Tribunal discutiu as consequências psicológicas dos abusos, ouvindo relatos das vítimas e de seus

47 International Criminal Court, Prosecutor v. Jean Pierre Bemba Gombo, $\mathrm{N}^{\circ}$ ICC-01/0501/08, 21 de junho de 2016, para. 25.

48 Clark, Janine Natalya, “The First Rape Conviction at the ICC”, Journal of International Criminal Justice, Oxford, vol. 14, núm. 3, 2016, pp. 679 e ss.

49 International Criminal Courtl, Prosecutor v. Jean Pierre Bemba Gombo, cit., para. 49 e ss.

50 Ibidem, para. 36. 
representantes legais que revelaram intenções suicidas e a ocorrência de transtorno do estresse pós-traumático. ${ }^{51}$ Há de se destacar, ademais, que o Tribunal foi levado a refletir também sobre os efeitos econômicos e sociais da violação. Nesse sentido, muitas vítimas relataram que foram rejeitadas ou excluídas socialmente, o que levou ao desemprego e consequentemente à desestruturação familiar. ${ }^{52}$

Neste ponto, cabe a seguinte indagação: Seria apropriado a um Tribunal Penal Internacional discutir de modo tão detalhado as maneiras que os abusos afetaram a vida e o cotidiano das pessoas? Poderia argumentar-se que não, pois ao relatar as consequências de um crime de tamanha gravidade, o acusado seria prejudicado em seu direito a um julgamento justo, ou ainda que às vítimas e testemunhas compete tão somente apresentar provas à Corte, e não expor suas necessidades ou emoções.

Porém, concordamos com Natalya Clark que o fato de a Câmara de Julgamento ter discutido os efeitos das violações e as necessidades das vítimas - a curto e longo prazo- é extremamente importante para o desenvolvimento da justiça penal internacional. Primeiro, porque individualiza as vítimas, ou seja, não são contadas apenas como números e estatística ou como meros instrumentos processuais para definição de culpa de um acusado. Em segundo lugar, há que se considerar que o TPI, a contrário dos tribunais internacionais que o antecederam, possui mecanismos para responder e reparar as necessidades das vítimas (veja-se por exemplo o poder estabelecido no Estatuto de Roma de determinar ações reparatórias e a criação do Trust Fund para beneficiar as vítimas). Portanto, ao conceder voz às vítimas para que tragam as suas realidades à sala de julgamento, dá-se a oportunidade ao TPI de superar algumas das circunstâncias sócio-políticas que condicionam a realidade pós-conflito, e, do mesmo modo, de desenvolver uma justiça que une o elemento retributivo ao restaurativo. ${ }^{53}$

\section{Análise dos propósitos do cometimento do crime}

Ao observar a jurisprudência do TPIY e TPIR, percebe-se que, em alguns casos, esses Tribunais refletiram acerca dos motivos que levaram os autores

51 Ibidem, para. 38.

52 Manning, Colin, op. cit., p. 12.

53 Clark, Janine Natalya, op. cit., p. 681. 
dos abusos sexuais a cometerem os seus atos. No caso Mucic, por exemplo, a Secção de Julgamento afirmou que os abusos foram cometidos como forma de obter informações, coagir a vítima ou puni-la pelos atos de terceiros. No caso Furundzija, percebeu-se, igualmente, que alguns dos abusos significavam uma punição pela não divulgação de informações que os acusados gostariam de obter. ${ }^{54}$

Do mesmo modo, a Secção de Julgamento em 1a. instância discutiu em Bemba Gombo os propósitos e motivos das violações cometidas pelos soldados do MLC. Porém, com uma característica importante: não se discutiram apenas os motivos imediatos, ou os propósitos que o ato em si pretendia alcançar; em vez disso, o Tribunal enfatizou os motivos socioeconômicos ou conjunturais que levaram os soldados a cometerem os crimes sexuais. Este fato se mostrou essencial para delimitar a extensão da responsabilidade criminal do oficial.

O Tribunal identificou que i) as tropas não recebiam uma compensação financeira adequada, e praticavam saques e violações como uma forma de "auto-compensação"; ${ }^{55}$ ii) alguns dos soldados diziam às vítimas que estavam famintos. Há de se levar em consideração que o modo de responsabilidade arguido nesse caso foi a responsabilidade de comando. ${ }^{56}$ Ora, se os soldados a cargo de Bemba Gombo estavam saqueando e violando por não estarem sendo pagos, a Secção de Julgamento entendeu que ele não havia tomado as medidas razoavelmente necessárias, dentro de seus poderes no contexto operacional específico do MLC, para reprimir ou evitar os crimes, e, assim, foi considerado culpado pela command responsibility. Com isso, a Secção de Julgamentos do TPI implicitamente afirmou que para se obter uma justiça criminal internacional adequada e proporcional, não basta adotar uma abordagem puramente centrada na vítima, mas deve-se analisar também os fatores macro e micro de causalidade que levaram ao cometimento dos crimes internacionais.

54 Para maiores desenvolvimentos sobre o tema, vide Fiske, Lucy and Shackel, Rita, "Ending Rape in War: How far Have We Come?" Cosmopolitan Civil Societies, Sydney, vol. 6, núm. 3, 2014, p. 127 e ss.

55 International Criminal Court, Prosecutor v. Jean Pierre Bemba Gombo, cit., para. 47.

56 Sacouto, Susana and Sellers, Patricia Viseur, "The BEMBA Appeals Chamber Judgment: Impunity for Sexual and Gender-Based Crimes", William \& Mary Bill of Rights Journal, Williamsburg, vol. 27, núm. 3, 2019, p. 599. 


\section{Decisão da Secção de Recursos}

Em junho de 2018, a Secção de Recursos do TPI absolveu Bemba Gombo, em uma decisão apertada (3-2). O Tribunal entendeu inter alia que a condenação havia excedido os fatos e circunstâncias descritas nas acusações e, portanto, a Secção de Julgamento não poderia ter emitido um veredito. ${ }^{57}$

A maioria da Secção de Recursos considerou que, tanto o Procurador, como o juízo de instrução, eram obrigados a detalhar todos os atos criminosos cometidos pelos soldados de Bemba e que, sem essa averiguação, a Secção de Julgamento não tinha permissão para incluir esses atos em sua decisão de condenação.

Para melhor esclarecimento do conteúdo dessa decisão, as etapas processuais no TPI podem ser resumidas em: inquérito, mandado de detenção, juízo de instrução, julgamento em primeira instância, e recursos. O artigo 61 do Estatuto de Roma trata da "apreciação da acusação antes do julgamento", prevendo que, num prazo razoável após a entrega da pessoa ao Tribunal ou a sua comparência voluntária, o juízo de instrução realizará uma audiência para apreciar os factos constantes da acusação com base nos quais o procurador pretende requerer o julgamento. Com base nos fatos apreciados durante a audiência, o juízo de instrução decidirá se existem provas suficientes de que o arguido cometeu os crimes que lhe são imputados. Caso decida afirmativamente, o juízo de instrução declarará procedente a acusação e remeterá o arguido para o juízo de julgamento em 1a. instância (artigo 61, 7).

O juízo de instrução surge da necessidade de uma verificação preliminar, desde o início, para garantir que existem evidências suficientes para justificar um julgamento, evitando, assim, detenções prolongadas, antes e durante o processo. A chamada "audiência de confirmação" foi projetada, nesse sentido, para eliminar os casos que claramente não têm base para prosseguir. Nesse momento do processo, o Procurador deve apresentar provas de que há "razões substanciais para acreditar" que a pessoa cometeu o crime alegado. Do mesmo modo, o juiz de instrução, para confirmar as acusações, precisa apenas atestar a existência dessas razões substanciais. Trata-se de um padrão que se situa entre o "motivos razoáveis para acredi-

57 International Criminal Court, The Prosecutor v. Jeajn-Pierre Bemba Gombo, cit., Judgment, para. 2 . 
tar" — necessário para ordenar detenção — e o "além de qualquer dúvida razoável” - para condenação. ${ }^{58}$

Importa destacar que os tribunais penais internacionais tradicionalmente empregaram padrões de precisão relativamente brandos nas acusações prévias ao julgamento, permitindo ao Procurador, inclusive, uma ampla latitude para emendar ou complementar as acusações. ${ }^{59}$ Basta referir que, no âmbito do Estatuto de Roma, antes da audiência de instrução, o Procurador pode reabrir o inquérito e alterar ou retirar parte dos fatos constantes da acusação, devendo ser o arguido notificado em tempo razoável, antes da realização da audiência (artigo $61^{\circ}, 4$ ); e, após declaração de procedência das acusações e antes do início do julgamento em 1a. instância, o procurador pode, mediante autorização do juízo de instrução e notificação prévia do arguido, alterar alguns fatos constantes da acusação (artigo 61, 9).

Com base nesse quadro normativo, e na jurisprudência da Corte, ocorreram o juízo de instrução e julgamento em 1a. instância de Bemba Gombo. Ao apreciar as alegações do réu, contudo, a Secção de Recursos considerou que "simplesmente listar as categorias de crimes pelos quais uma pessoa deve ser acusada ou declarar, em termos gerais, os parâmetros temporais e geográficos da acusação" ${ }^{00}$ não são suficientes para cumprir os requisitos das regras do Tribunal e não permite uma aplicação significativa do artigo 74 (2) do Estatuto, i.e., julgamento em primeira instância.

Alex Whiting apresenta críticas à decisão, no sentido de que os procedimentos no TPI precisam ser interpretados e aplicados de uma maneira que garanta que os direitos do acusado sejam totalmente protegidos, ao mesmo tempo que se reconheça que os processos de atrocidades internacionais são extremamente complexos e dinâmicos, especialmente quando as acusações são contra comandantes por crimes em massa. A esse respeito, um caso do TPI não pode ser comparado a um caso doméstico usual, no qual a maioria, senão todas as evidências, podem ser obtidas e "trancadas" muito antes do julgamento. No caso Bemba, 17 meses se passaram entre a decisão de

58 Whiting, Alex, "Appeals Judges Turn the ICC on its Head with Bemba decision”, Just Security, 2018. Disponível em: https://www.justsecurity.org/57760/appeals-judges-turn-icc-hea d-bemba-decision.

59 Middle East and North Africa Financial Network, "Bemba acquittal overturns important victory for sexual violence victims", 2018.

60 International Criminal Court, The Prosecutor v. Jeajn-Pierre Bemba Gombo, cit., Key Findings, para. 4. 
confirmação e o início do julgamento; durante esse período, novas evidências surgem. Desde que o réu receba notificação adequada das acusações e provas contra ele, como ocorreu neste caso, não há razão para que novas evidências não se tornem parte do julgamento e, de fato, seria injusto deixá-las de fora. ${ }^{61}$

A decisão também traz implicações ao trabalho do Procurador. Com efeito, a Procuradora do TPI, após o julgamento, demonstrou preocupação em relação à maneira pela qual a Acusação deveria doravante investigar casos que envolvem criminalidade em massa.

O nível de detalhe que o Procurador pode agora ser requerido a incluir nas acusações pode dificultar o julgamento de casos futuros que envolvam extensas campanhas de vitimização, especialmente quando o acusado não é um perpetrador direto, mas um comandante distante da cena do suposto crimes, mas que podem assumir responsabilidade criminal como superior, tendo controle efetivo sobre os autores, seus subordinados. ${ }^{62}$

No mesmo sentido, a decisão final desperta atenção quanto aos critérios e aplicação da revisão das provas. De acordo com o entendimento da Secção de Recursos, é de sua responsabilidade avaliar se a Secção de Julgamento aplicou ou não o standard of proof corretamente. $\mathrm{O}$ acusado não precisa provar que a secção de julgamento cometeu um erro de fato. É suficiente identificar fontes de dúvida sobre a precisão das constatações da secção de julgamento para obrigar a secção de recursos a revisar independentemente o raciocínio da secção de julgamento com base nas evidências disponíveis. ${ }^{63}$ Assim, "a Secção de Recursos deve estar convencida de que as constatações factuais feitas além de qualquer dúvida razoável são claras e inatacáveis, tanto em termos de evidência quanto de justificativa. Consequentemente, quando a Secção de Recursos for capaz de identificar descobertas que possam ser razoavelmente colocadas em dúvida, deve revogá-las". ${ }^{64}$

61 Whiting, Alex, op. cit., p. 2.

62 "Statement of ICC Prosecutor, Fatou Bensouda, on the Recent Judgment of the ICC Appeals Chamber Acquitting Mr Jean-Pierre Bemba Gombo", 13 de junho de 2018. Disponível em: https: / / www.icc-cpi.int/Pages/item.aspx? name=180613-OTP-stat.

63 International Criminal Court, The Prosecutor v. Jeajn-Pierre Bemba Gombo, cit., Key Findings, para. 2 .

${ }^{64}$ Ibidem, para. 3. 
A Procuradora do TPI considera que a maioria da Secção de Recursos afastou-se do modelo tradicional de revisão de erros factuais, que havia sido aplicado de forma consistente não apenas pela Secção de Recursos do TPI, mas também pelos Tribunais ad hoc da ONU. De acordo com esse padrão tradicional de revisão, a Secção de Recursos normalmente defere a avaliação das evidências feitas pela Secção de Julgamento, a menos que a parte apelante demonstre que esta não poderia ter razoavelmente alcançado as conclusões de fato sobre as evidências disponíveis. Aparentemente, a maioria deixou de lado esse teste, substituindo-o por uma abordagem que sugere que, quando a própria Secção de Recursos conseguir identificar descobertas que possam ser razoavelmente colocadas em dúvida, elas devem ser anuladas.

Leila Sadat traz à reflexão que as Secções de Julgamento foram normativamente arquitetadas e posicionadas para ouvir, avaliar e pesar as provas apresentadas no julgamento, de tal forma que a Secção de Recursos deve conferir uma "margem de deferência" à avaliação das provas pela Secção de Julgamento. Ademais, qualquer afastamento de decisões anteriores deve ser feito com cautela e a devida justificação, sob o risco de se pôr em xeque a própria consistência, previsibilidade e autoridade do sistema jurídico. ${ }^{66}$

Alex Whiting leciona que essa nova abordagem permite à Secção de Recursos revisar todo o processo e chegar a sua própria conclusão, sem levar em consideração as conclusões da Secção de Julgamento. No caso concreto, prossegue o autor, "foi precisamente o que a Secção de Recursos fez, selecionou algumas evidências com as quais discordou e baseou-se nelas para chegar a uma conclusão diferente sobre a culpabilidade de Bemba, com um foco particular na questão de saber se ele fez tudo o que pôde para impedir ou reprimir crimes de seus soldados", ${ }^{67}$ que passamos a analisar a seguir.

A Secção de Recursos reconsiderou a condenação de Bemba sob a responsabilidade de comando. Entendeu que a Secção de Julgamento determinou indevidamente que Bemba não tomou as medidas "necessárias e razoáveis" para impedir ou punir os seus subordinados pela prática de crimes

65 Idem.

66 Sadat, Leila, "Fiddling while Rome Burns? The Appeals Chamber's Curious Decision in Prosecutor v. Jean-Pierre Bemba Gombo", EJIL TALK!, 2018. Disponível em: https://www.ejiltalk. org/fiddling-while-rome-bums-the-appeals-chambers-curious-decision-in-prosecutor-v-jean-pierrebemba-gombo.

67 Whiting, Alex, op. cit., p. 2, tradução nossa. 
internacionais. ${ }^{68}$ Em particular, afirmou que foram feitas interpretações sem fundamento sobre a intenção de Bemba, e questionou o uso, pela Secção de Julgamento, de um padrão de conduta sobre o que Bemba deveria ter feito, sem o réu ter sido anteriormente informado desse padrão. ${ }^{69}$

A decisão, nesse ponto, tem recebido críticas da doutrina. Diane Amann defende que a elaboração de uma lista de medidas que deveriam ter sido tomadas pelo comandante, como forma de determinar se o réu fez ou não tudo o que podia para impedir os crimes de suas tropas, é a maneira razoável e tradicional de se averiguar a responsabilidade. ${ }^{70}$ De fato, a Secção de Julgamento em Bemba fez isso. Mas a Secção de Recursos objetou ao uso dessa forma de responsabilização, caracterizando esse uso de listagem como um aviso não noticiado previamente e injusto ao réu de que tais possibilidades seriam levadas em consideração. Para Anman, a decisão acaba por evidenciar "pouca consideração pelas raízes éticas da doutrina que impõe deveres adicionais de cuidado aos líderes militares; a maioria transformou, assim, a responsabilidade de comando em uma advertência com pouco efeito, um fardo legal facilmente evitado". ${ }^{71}$ Embora não pertença ao escopo primário do presente trabalho, concordamos com Gurgen Petrossian que essa absolvição é um exemplo claro de que a doutrina da responsabilidade de comando ainda está em desenvolvimento na seara internacional ${ }^{72}$.

O julgamento de Bemba pode sinalizar uma mudança de direção para o TPI, no sentido de que outros casos também apresentaram ambiguidades e inconsistências processuais, com desfechos diferentes. No caso Lubanga, por exemplo, todos os testemunhos foram anulados. Lubanga ainda foi condenado, mas recebeu uma sentença relativamente leve. ${ }^{73} \mathrm{O}$ caso Bemba, diferentemente, é o primeiro que resultou em absolvição. Apesar de absol-

68 International Criminal Court, The Prosecutor v. Jeajn-Pierre Bemba Gombo, cit., Mertis, para. 138 .

69 Ibidem, para. 7.

70 Amann, Diane Marie, "In Bemba and Beyond, Crimes Adjudged to Commit Themselves", EJIL TALK!, 2018. Disponível em: https://www.ejiltalk.org/in-bemba-and-beyond-crimes -adjudged-to-commit-themselves.

71 Idem.

72 Petrossian, Gurgen, "Elements of Superior Responsibility for Sexual Violence by Subordinates, Manitoba Law Journal, Winnipeg, vol. 42, núm. 3, 2019, p. 125.

73 International Criminal Court, Prosecutor v. Thomas Lubanga Dyilo. No: ICC-01/04$01 / 06$ A 5 . 
vições como essa, por questões processuais, trazerem uma sensação, em especial para as vítimas, de que a justiça material não foi satisfatoriamente alcançada, argumenta-se, por outro lado, que constituem o preço que deve ser pago para manter os princípios fundamentais de equidade e integridade do processo judicial.

\section{CONCLUSÕES}

O reconhecimento das múltiplas formas de violência sexual como crimes internacionais tem sido lento e, por vezes, inconsistente. Os desenvolvimentos mais importantes, tanto no plano material como no plano processual, ocorreram nos Tribunais Penais Internacionais para Ruanda e para a Iugoslávia. Esses desenvolvimentos foram posteriormente consolidados e expandidos pelo Tribunal Penal Internacional, que hoje tem à sua frente o desafio de, enquanto depositária da confiança de 124 países, processar e julgar os crimes considerados mais graves para a comunidade internacional, além de oferecer, de algum modo, medidas reparatórias às vítimas, de forma que possam ter reconstruídas suas vidas no período pós-conflito.

Ao atribuir a Bemba a responsabilidade pelas violações cometidas por combatentes sob seu comando, o julgamento de 2016 foi considerado um importante avanço para o direito penal internacional, por tornar a violência sexual um elemento central das acusações, algo que até então se mostrava ausente das sentenças e acusações no âmbito do direito internacional penal.

Lamentavelmente, no caso mais grave de violência sexual e de gênero decidido por um Tribunal Internacional até o momento, quando há uma necessidade aguda de enviar um sinal claro, a nível global, de que tais crimes repulsivos não devem ficar impunes, a decisão final ficou caracterizada por um afastamento "significativo e inexplicável" 74 da jurisprudência anterior da Corte e substituição por novas, incertas e não testadas normas.

Da absolvição inesperada e apertada de Bemba Gombo, cumpre-nos enfatizar que, quase duas décadas após a entrada em vigor do Estatuto de Roma,

74 Statement of ICC Prosecutor, Fatou Bensouda, on the recent judgment of the ICC Appeals Chamber acquitting Mr Jean-Pierre Bemba Gombo, 13 de Junho de 2018, https: / / www. icc-cpi.int/Pages/item.aspx? name=180613-OTP-stat. 
momento em que se vem solidificando o papel primordial do TPI para uma eficaz proteção multinível dos direitos humanos, essa Corte ainda não emitiu uma única decisão condenatória final por crimes de violência sexual.

\section{BIBLIOGRAFIA}

Amann, Diane Marie, "In Bemba and Beyond, Crimes Adjudged to Commit Themselves", EJIL TALK!, 2018. Disponível em: https: / /www.ejiltalk. org/in-bemba-and-beyond-crimes-adjudged-to-commit-themselves.

Buss, Doris, "Rethinking Rape as a Weapon of War", Feminist Legal Studies, vol. 17, núm. 2, 2009.

CLARK, Janine Natalya, “The First Rape Conviction at the ICC”, Journal of International Criminal Justice, Oxford, vol. 14, núm. 3, 2016.

Ferreira de Almeida, Francisco, Direito internacional público, 2a. ed., Coimbra, Coimbra Editora, 2003.

FERREIRA DE AlmeIDA, Francisco, Os crimes contra a humanidade no actual direito internacional penal, dissertação para doutoramento em Ciências Jurídico-Políticas pela Faculdade de Direito da Universidade de Coimbra, Coimbra, 2007.

FIDALGO, Sofia, "Os crimes sexuais no direito internacional penal”, Boletim da Faculdade de Direito, Coimbra, vol. 83, 2007.

FISKE, Lucy e SHACKEL, Rita, "Ending Rape in War: How far Have We Come?” Cosmopolitan Civil Societies, Sydney, vol. 6, núm. 3, 2014.

FitzGERALD, Kate, "Problems of Prosecution and Adjudication of Rape and other Sexual Assaults under International Law”, European Journal of International Law, vol. 8, núm. 4, 1997.

Goethe-InstituT DE LisbOA, Direito penal internacional para a proteção dos direitos humanos, Lisboa, Fim de Século Edições, 2003.

JOSEPH, Sarah e KYRIAKAKIS, Joanna, "The United Nations and Human Rights", JOSEPH, Sarah e MCBETH, Adam (eds.), Research Handbook on International Human Rights Law, Cheltenham, Edward Elger, 2010.

Kaul, Hans Peter, "The Protection of Human Rights through the International Criminal Court as a Contribution to Constitutionalization and Nation-Building", Human Rights-International Criminal Court, The 
Hague, 2011. Disponível em: https://www.icc-cpi.int/NR/rdonlyres/33E 021 F0-8672-4210-8170-790E380A1AA1/282948/FINAL_Speech_Pa nel3_ICC_Features_Challenges.pdf.

MACHADO, Jónatas, Direito internacional: do paradigma clássico ao pós-11 de setembro, 3a ed., Coimbra, Coimbra Editora, 2003.

Manning, Colin, Development of International Criminal Law of Sexual Violence, SSRN, 2016. Disponível em: https: / / ssrn.com / abstract $=2728700$.

Mazzuoli, Valério de Oliveira, Curso de direito internacional público, 10a. ed., São Paulo, Revista dos Tribunais, 2016.

NJoroge, Fraciah Muringi, "Evolution of Rape as a War Crime and a Crime against Humanity”, SSRN, 2016. Disponível em: https://ssrn.com/ abstract $=2813970$.

Paulus, Andreas, "Do direito dos Estados ao direito da humanidade? A instituição de um Tribunal Penal Internacional e o desenvolvimento do Direito Internacional”, Direito Penal Internacional para a Proteção dos Direitos Humanos, Lisboa, Fim de Século Edições, 2003.

Petrossian, Gurgen, "Elements of Superior Responsibility for Sexual Violence by Subordinates, Manitoba Law Journal, Winnipeg, vol. 42, núm. 3, 2019.

PiOvesan, Flávia e Kamimura, Akemi, "Proteção internacional à diversidade sexual e combate à violência e discriminação baseadas na orientação sexual e identidade de gênero", Anuario de Derecho Público, Santiago de Chile, núm. 1, 2017.

QUITTER, Bridget, "Rape as a War Crime-Prosecution of Sexual Violence in the International Community”, SSRN, 2013. Disponível em: https: / / ssrn.com / abstract $=2498208$.

Sacouto, Susana e Sellers, Patricia Viseur, "The BEMBA Appeals Chamber Judgment: Impunity for Sexual and Gender-Based Crimes", William \&Mary Bill of Rights Journal, Williamsburg, vol. 27, núm. 3, 2019.

SADAT, Leila, "Fiddling while Rome Burns? The Appeals Chamber's Curious Decision in Prosecutor v. Jean-Pierre Bemba Gombo", EJIL TALK!, 2018. Disponível em: https: / / www.ejiltalk.org/fiddling-while-rome-bums-the-appealschambers-curious-decision-in-prosecutor-v-jean-pierre-bemba-gombo.

SouZA, Jefferson Lima de, "O diálogo entre o Tribunal Constitucional Português e o Tribunal Europeu dos Direitos do Homem e seu impacto na proteção dos direitos fundamentais”, em MARTINS, Ana Maria Guerrra 
(coord.), A proteção multinível dos direitos fundamentais: estudos sobre diálogo judicial, Lisboa, AAFDL, 2019.

Steiner, Sylvia, "Discurso de abertura", em Albuquerque, Paulo Pinto e SiLVA, João Miguel (orgs.), O Tribunal Penal Internacional e a transformação do direito internacional, Lisboa, Universidade Católica Editora, 2006.

Whiting, Alex, "Appeals Judges Turn the ICC on its Head with Bemba decision”, Just Security, 2018. Disponível em: https://www.justsecurity. org/57760/appeals-judges-turn-icc-head-bemba-decision.

Zorrila, Maider, La Corte Penal Internacional ante el crimen de violencia sexual, Bilbao, Universidad de Deusto-Instituto de Derechos Humanos, 2005. 